\title{
The Relationship between Teaching Efficacy and Job Satisfaction of Special School Teachers after In-Service Training: Analysis of the Mediating Effect of Organizational Commitment
}

\author{
Xin Wei ${ }^{\text {a }}$, Hongye Wang ${ }^{\text {b, * }}$, Qiuzhu Liu ${ }^{c}$, Xiaoli Yang ${ }^{d}$ \\ School of special education, Leshan Normal University, Leshan, Sichuan 614000, China \\ a12872204@qq.com, b, *248277872@qq.com, “497265086@qq.com, d452111526@qq.com
}

\begin{abstract}
To investigate teaching efficacy of the special education teachers by training, and explore the relationship among organizational commitment, job satisfaction and teaching effectiveness, this research makes a survey of 616 teachers from 37 special schools in Sichuan Province. Results found that special schools attach greater importance to teacher training. In-service training of teachers has significant influence to teacher efficacy. Affective commitment and normative commitment are mediators between the personal teaching efficacy and job satisfaction, and they are partially mediated by the general teaching efficacy and job satisfaction.
\end{abstract}

Keywords: teaching efficacy; job satisfaction; organizational commitment; in-service training of teachers; special education teachers.

\section{Introduction}

The "Outline of National Medium and Long-Term Program for Education Reform and Development" points out that "special education is the basic way to promote the comprehensive development of disabled people and help disabled people to better integrate into society." In order to promote the development of special education, it is necessary to "strengthen team building of special education teachers." The level of teaching efficacy is related to whether teachers have the willingness to work hard and constantly improve the internal motivation of their teaching quality. The concept of teachers' teaching efficacy sense is an extension of Bandura's concept of self-efficacy, it refers to teachers' subjective judgment in their teaching activities on whether they can successfully complete teaching tasks and thus affect students' learning [1]. The sense of teaching efficacy includes general teaching efficacy and personal teaching efficacy. The general sense of teaching efficacy involves teachers' general views on education; it believes that education can affect students' development without being influenced by students' IQ and environment, personal sense of teaching efficacy involves teachers' affirmation of their own abilities and believes that they have the ability to influence students' learning [2].

Some studies have pointed out that there is a significant positive correlation between teachers' teaching efficacy and job satisfaction, and teaching efficacy has a positive predictive effect on job satisfaction [3]. The survey for special education teachers also presented consistent conclusions, the studies believe that the job satisfaction of special education teachers is above-average, and the general sense of teaching efficacy also has a positive predictive effect on job satisfaction [4]. The improvement of teaching efficacy helps to improve the job satisfaction of special education teachers.

The organizational commitment reflects the individual's loyalty to the organization and it is of great significance to the continuous development of the organization. The teacher's organizational commitment is that teachers recognize and accept the values of the school, contribute for the school spontaneously according to the school's norms, and are eager to continue working in the school [5]. The study found that there is a significant positive correlation between organizational commitment and job satisfaction, in a rural primary school teacher's research, it can be found that organizational commitment has a positive predictive effect on teacher job satisfaction [6], and research on university teachers is also consistent. [7].

Therefore, according to the existing research, there is a correlation among teachers' teaching efficacy, organizational commitment and job satisfaction. In order to further explore the relationship 
among the three in special education, this study intends to assume that the organizational commitment of special education teachers plays a mediating role between teaching efficacy and job satisfaction.

\section{Research Methods}

\subsection{Research Objects}

The study conducted a questionnaire FOR teachers from 37 special education schools in 16 cities and counties in Sichuan, including Chengdu, Nanchong, Yibin, Dazhou and Xichang. A total of 650 questionnaires were distributed, and 616 questionnaires were finally returned, the recovery rate is 94.77\%. Among the teachers surveyed, there were 456 female teachers, which account for $74.8 \%$, and 154 male teachers, which account for $25.2 \%$, among them, 547 teachers participated in in-service training, which account for $88.8 \%$ of the total number.

\subsection{Research Tools}

\subsubsection{Teaching Efficacy Scale}

The scale uses the teacher's teaching efficacy scale worked out by Yu Guoliang et al. (1995) [1], the scale has a total of 27 items, including two dimensions: individual teaching efficacy and general teaching efficacy. The scale uses 6 points for grading, from 1 complete disapproval to 6 full approval, the higher the score, the higher the teaching efficacy. In this study, the total internal consistency reliability of the scale was 0.89 , the internal consistency reliability of personal teaching efficacy was 0.81 , and the internal consistency reliability of general teaching efficacy was 0.84 .

\subsubsection{Organizational Commitment Scale}

The scale was worked out by Meyer and Allen (1997), [8], which is used to describe an individual's commitment to the organization, including emotional commitment, continuous commitment, and normative commitment. Emotional commitment refers to the individual's emotional attachment, identity and commitment to his or her organization; normative commitment reflects the pressure on the individual based on organizational socialization; continuous commitment involves the individual's perception of the loss caused by leaving. The scale has a total of 18 items, 5 points is used for grading, from 1 complete disapproval to 5 full approval, the higher the score, the higher the work commitment. In this study, the total internal reliability of the scale is 0.71 , and the internal consistency reliability of each dimension is between 0.62-0.67.

\subsubsection{Job Satisfaction Scale}

The scale was worked out by Spector (1985) [9], the scale has a total of 36 items, 5 points is used for grading, from 1 complete disapproval to 5 full approval, the higher the score, the higher job satisfaction. The internal consistency reliability in this study was 0.90 .

\subsection{Data Processing}

All data were statistically analyzed by using SPSS 20.0.

\section{Research Results}

\subsection{Analysis of the Influence of Special Education Teachers' In-service Training on Teachers' Teaching Efficacy}

\subsubsection{Analysis of the Situation of Special Education Teachers Participating in In-Service Training}

As can be seen from the number of special education teachers participating in the training, as shown in Table 1, only $11.2 \%$ of the special education teachers surveyed have not participated in inservice training, and the remaining $88.8 \%$ of the teachers have participated in various forms of inservice training, and most teachers have participated in different types of training programs 
continuously or multiple times. The survey also showed that there were 245 people who participated in the "National Training Program" and 478 people who participated in the "Provincial Training Program", in addition, some teachers in the interview also said that they have participated in many trainings organized by the city Disabled Persons' Federation, from the training content, includes education and teaching training courses (such as intellectual education, deaf student education, personalized education, etc.), as well as educational rehabilitation courses (such as physical rehabilitation, art rehabilitation, speech language etc.). It can be seen that this is related to various initiatives in recent years in cities and prefectures in Sichuan Province to actively carry out the professional development ability of special education teachers.

Table 1. Number of special education teachers participating in in-service training

\begin{tabular}{ccccc}
\hline & 0 & one-two times & three-five times & more than five times \\
\hline number of people $(\mathrm{N})$ & 69 & 248 & 125 & 174 \\
percentage $(\%)$ & 11.2 & 40.3 & 20.3 & 28.2 \\
\hline
\end{tabular}

\subsubsection{Difference Inspection in the Number of In-service Training Times on the Teaching Efficacy of Special Education Teachers}

The F-test of the number of in-service training on the teaching efficacy of special education teachers, as shown in Table 2, the individual teaching efficacy and general teaching efficacy all reach a significant level, there are $\mathrm{F}=9.45, \mathrm{P}<0.001 ; \mathrm{F}=5.62, \mathrm{P}<0.01$. The LSD post-test showed that the individual teaching efficacy of teachers who did not participate in the training was lower than that of the teachers who participated in the training, but the difference was not significant with the teachers who trained 1-2 times $(\mathrm{P}>0.05)$, the difference was significant with teachers who participated in 3-5 times and 5 times or more $(\mathrm{P}<0.001)$, teachers who participated in 1-2 trainings had lower personal teaching efficacy than teachers who participated in 3-5 times and more than 5 times, and the differences were also significant $(\mathrm{P}<0.01, \mathrm{P}<0.001)$. The general teaching efficacy of teachers who participated in 1-2 trainings was significantly lower than that of non-involved teachers $(\mathrm{p}<0.05)$, but also significantly lower than that of teachers who participated in 3-5 times and more than 5 times $(\mathrm{P}<0.05, \mathrm{P}<0.001)$. From the research results, it can be seen that the teachers who participated in the training more than 3 times may have a significant impact on their improvement of teaching efficacy.

Table 2. F-test and post-test of the number of in-service training on the teaching efficacy of special education teachers

\begin{tabular}{cccc}
\hline & & $M \pm S D$ & $F$ \\
\hline personal teaching efficiency & & & $7.69^{* * *}$ \\
participate in training 0 times & participate in training 1-2 times & $-0.14 \pm 0.09$ & \\
& participate in training 3-5 times & $-0.37 \pm 0.10^{* * * *}$ & \\
& participate in training over 5 times & $-0.40 \pm 0.10^{* * *}$ & \\
participate in training 1-2 times & participate in training 3-5 times & $-0.23 \pm 0.07^{* *}$ \\
& participate in training over 5 times & $-0.26 \pm 0.07^{* * *}$ \\
general teaching efficiency & & \\
participate in training 1-2 times & participate in training 0 times & $-0.27 \pm 0.12^{*}$ & \\
& participate in training 3-5 times & $-0.21 \pm 0.09^{*}$ & \\
& participate in training over 5 times & $-0.33 \pm 0.08^{* * * *}$ & \\
\hline
\end{tabular}

Note: $* \mathrm{P}<0.05, * * \mathrm{P}<0.01, * * * \mathrm{P}<0.001$, the same below. 


\subsection{Relevant Analysis of Teachers' Teaching Efficiency, Organizational Commitment and Job Satisfaction in In-service Training}

After excluding the special education teachers who did not participate in the training, 547 teachers who participated in the training more than once were analyzed for their sense of teaching efficacy, organizational commitment and job satisfaction, as shown in Table.3, there are two positive correlations in personal teaching efficacy, general teaching efficacy, emotional commitment, normative commitment and job satisfaction. The significant correlation was $\mathrm{P}<0.01$.

Table 3. correlation analysis of teaching efficacy, organizational commitment and job satisfaction of special education teachers in in-service training

\begin{tabular}{|c|c|c|c|c|c|}
\hline & $\begin{array}{c}\text { Personal } \\
\text { Teaching } \\
\text { Efficiency }\end{array}$ & $\begin{array}{c}\text { general teaching } \\
\text { efficacy }\end{array}$ & $\begin{array}{l}\text { affective } \\
\text { commitment }\end{array}$ & $\begin{array}{l}\text { normative } \\
\text { commitment }\end{array}$ & $\begin{array}{c}\text { job } \\
\text { satisfaction }\end{array}$ \\
\hline $\begin{array}{l}\text { personal } \\
\text { teaching efficacy }\end{array}$ & 1 & & & & \\
\hline $\begin{array}{l}\text { general teaching } \\
\text { efficacy }\end{array}$ & $0.47 * *$ & 1 & & & \\
\hline $\begin{array}{l}\text { emotional } \\
\text { commitment }\end{array}$ & $0.34 * *$ & $0.21 * *$ & 1 & & \\
\hline $\begin{array}{c}\text { normative } \\
\text { commitment }\end{array}$ & $0.14 * *$ & $0.12 * *$ & $0.61 * *$ & 1 & \\
\hline job satisfaction & $0.27 * *$ & $0.31 * *$ & $0.44 * *$ & $0.48 * *$ & 1 \\
\hline
\end{tabular}

\subsection{Analysis of the Mediating Effect of Organizational Commitment on Teaching Efficacy and Job Satisfaction}

There is a correlation between the teaching efficacy, organizational commitment and job satisfaction of special education teachers who participate in in-service training, therefore, it meets the preconditions of mediating effect analysis, and further analyzes the teaching efficacy and organization of in-service special education teachers. according to the steps of mediating analysis, the teaching efficacy is the independent variable, the organizational commitment is the mediator variable, the job satisfaction is the dependent variable, and the hierarchical regression analysis is carried out. First, after controlling the gender, age, and training times $(\mathrm{F}=2.138, \mathrm{P}>0.05)$, the first layer puts a sense of personal teaching efficacy and general teaching efficacy; the second layer puts emotional commitment and normative commitment. The results of the regression model are as shown in Table 4. Personal sense of teaching efficacy and general teaching efficacy all have a significant positive prediction of job satisfaction, after adding emotional commitment and normative commitment, the job satisfaction still has a significant positive predictive effect. And the explanatory power of the regression equation increased from 0.12 to 0.32 , and the interpretation rate increased by $20 \%$. Among them, the path coefficient of personal teaching efficacy decreased, and it changed from significant to insignificant, this indicates that the personal teaching efficacy of in-service training special education teachers has a complete intermediary in the impact of emotional satisfaction and normative commitment on their job satisfaction. The path coefficient of general teaching efficacy is also reduced, but it is still significant. This shows that the emotional commitment and normative commitment of in-service special education teachers play a partial intermediary role in teachers' general teaching efficacy and job satisfaction. 
Table 4. Mediating effect of organizational commitment on teaching efficacy and job satisfaction of in-service special education teachers

\begin{tabular}{|c|c|c|c|c|c|c|c|}
\hline & \multicolumn{2}{|c|}{$M 1$} & \multicolumn{2}{|c|}{ M2 } & \multirow{2}{*}{$R$} & \multirow{2}{*}{$\triangle R^{2}$} & \multirow{2}{*}{$F$} \\
\hline & $\Delta \beta$ & $t$ & $\Delta \beta$ & $t$ & & & \\
\hline \multicolumn{8}{|l|}{ job satisfaction } \\
\hline first layer & & & & & 0.35 & 0.12 & $15.16^{* * *}$ \\
\hline personal teaching efficacy & 0.16 & $3.40 * *$ & 0.08 & 1.92 & & & \\
\hline personal teaching efficacy & 0.24 & $5.10^{* * *}$ & 0.20 & $4.78^{* * *}$ & & & \\
\hline second layer & & & & & 0.57 & 0.32 & $36.32 * * *$ \\
\hline emotional commitment & 1.60 & $3.36^{* *}$ & & & & & \\
\hline normative commitment & 0.35 & $7.59 * * *$ & & & & & \\
\hline
\end{tabular}

\section{Conclusion}

\subsection{Analysis of the Basic Situation of Post-Service Training of Special Teachers}

Among the surveyed special education teachers, $88.8 \%$ have participated in national or provincial training programs. It can be seen that with the suggestions of the state council and the ministry of education on "vigorously strengthening the construction of special education teachers", provinces and cities have paid more attention to teachers' professional development needs and on-the-job training in recent years $[10,11]$. Relying on educational platforms such as universities and colleges, through the integration of educational resources, teachers of special schools have the opportunity to "go out" to consult and learn cutting-edge issues in this field from industry experts. Meanwhile, they can also learn from teaching experience through peer to peer communication, so as to encourage progress together. However, only $11.2 \%$ of the teachers in the survey said that they had not participated in the training, and the survey found that $56.5 \%$ of these teachers were young teachers under the age of 30 . This also basically conforms to the special school to the teacher development plan. Special-education schools in recent years, the degree of teachers introduction in a trend of increased gradually, the young teacher who have just graduated from university into the TeJiao, on the one hand to the forefront of special education in the university the problem still keep in a state of learning, on the other hand also need to allow time for the new position to actively adapt to the new teaching environment and tasks, so it can be compared to young teachers, senior teachers are relatively few involved in training programs.

\subsection{Influence of Post-service Training on Teaching Efficacy of Special Teachers}

Teachers' knowledge, skills and successful experience in work are important conditions to promote teachers' teaching efficacy [12]. From the results of the survey, special-education teachers' personal teaching efficacy increased with the increase of number of training, and reached the significant level, and through the test results can be found, not participated in training and training 1-2 times no significant difference of teachers' personal teaching efficacy, and fewer training (three times) or not to participate in the training of teachers and training more than 3 times and teachers' personal teaching efficacy is significant differences. It can be inferred that more training times, especially continuous training in specific fields, will positively promote the improvement of teachers' teaching ability. The research points out those teachers with high sense of efficacy are more willing to constantly change teaching methods and use a variety of teaching strategies to achieve teaching objectives [13]. In the short-term, temporary teaching study, shortage of special-education teacher professional depth will be training effect [14] [15], but through the training for many times, the participation of teachers understanding of learning field can have a continuous and systematic understanding, also more willing to learn new ideas, methods, fusion to try in the classroom teaching, training in promoting teachers' teaching ability at the same time also let teachers develop higher self-assessment. The general teaching efficacy of teachers was significantly lower than that of teachers who participated 
in training for 1-2 times. The general teaching efficacy of teachers is the general concept and attitude of teachers to education. Generally, the general teaching efficacy of new teachers is higher, because they believe that education can change the current situation of students. Studies have also pointed out that teachers in special schools generally have a positive sense of teaching efficacy [16] and show a higher tendency than teachers in general schools, which may be related to the idea that special education teachers attach more importance to the needs of special children to improve their social adaptability through education [17]. But special children is different from ordinary students, difficulty is big, in the process of education and limited is low, this may make teachers' general teaching selfefficacy as the growth of the teaching time and reduce, but it is worth noting that the general selfefficacy of teaching training teachers for more than 3 times and showed a trend of gradually increased, visible continuous study way, targeted training, can improve the ability of teacher education, reduce the occurrence of occupational burnout.

\subsection{Analysis of the Relationship between Post-service Training Teachers' Teaching Efficacy, Organizational Commitment and Job Satisfaction}

In the test of mediating effect, affective commitment and normative commitment play a full mediating role between the personal teaching efficacy and job satisfaction of special education teachers, and a part mediating role between the general teaching efficacy and job satisfaction. This also confirms the hypothesis of this study, showing that teachers' teaching efficacy can have a direct impact on job satisfaction on the one hand, and can also have an indirect impact on job satisfaction through teachers' emotional commitment and normative commitment. It can be seen that the more confident teachers are in their teaching ability, the more they can enhance their sense of identity and sense of belonging to the school, and the more they are willing to fulfill their duties in accordance with the norms and obligations of the school, and the more likely they are to inspire individual happiness and satisfaction, which is consistent with existing studies [18]. The study also found that when teachers' emotional commitment and normative commitment entered into the regression equation, the interpretation rate increased from $12 \%$ to $32 \%$, indicating that teachers' emotional commitment and normative commitment have higher explanatory power to job satisfaction than teaching efficacy. Organizational commitment reflects the professional identity special-education teacher for special education and willingness to job involvement, organizational commitment of teachers for special education career will have stronger emotional input, more able to work with enthusiasm, compared to other teachers, teaching effectiveness is gained by the larger, more on the effect of job satisfaction. Therefore, this suggests that in post-service training for special education teachers, in addition to improving teachers' knowledge and skills, more psychological support can be provided from professional emotion, occupational investment and other aspects.

\section{Conclusion}

(1) At present, special schools pay more attention to in-service training, and a large proportion of special-education teachers participate in training.

(2) The teaching efficacy of teachers who have received three or more in-service trainings has been significantly improved.

(3) Emotional commitment and normative commitment in organizational commitment play a full mediating role between individual teaching efficacy and job satisfaction of special education teachers, and a partial mediating role between general teaching efficacy and job satisfaction.

\section{Acknowledgements}

Fund Project: This article is the phased research result of "A follow-up Study on Special Education Promotion Plan (2014-2016)"(Project NO.: DGA150225), which is the National Education Science "Twelfth Five-Year Plan"2015 key project of the Ministry of Education. 


\section{References}

[1]. Guo liang Yu, Tao Xin, Ji liang Shen. Teachers' sense of teaching efficacy: its structure and influencing factors. Acta Psychologica Sinica. Vol. 27 (1995) No. 2, p. 159-166.

[2]. Guo liang Yu, Xiao lu Luo. A study of teaching efficacy and its correlation factors. Journal of Beijing Normal University (Social Sciences). (2000) No. 1, p. 72-79.

[3]. Ping Zhang, Min gui Ge. An analysis of the relationship between teaching efficacy and job satisfaction of primary and middle school teachers. Journal of Teaching and Management. (2013) No. 4, p. 22-24.

[4]. Na Zhao. A study on the relationship between teachers' teaching efficacy and job satisfaction in special education schools. Journal of Suihua University. Vol.33(2013) No. 10, p. 11-15.

[5]. Ai hong Song, Yong hong Cai. Teacher organizational commitment construct: confirmatory factor analysis. Psychological Development and Education. (2005) No. 2, p. 48-51.

[6]. Qian Gu. Job Satisfaction and organizational commitment of teachers in rural primary schools. China Journal of Health Psychology. Vol 21(2013) No.8, p. 1196-1197.

[7]. Feng qiang Gao, Dong yan Qi, Xiao li Liu. The relation between organization promise, job satisfaction and job burnout of college teachers. Journal of Shandong University of Technology (Social Sciences). Vol.27(2011) No.5, p. 91-95.

[8]. Dail Lfields. A guide to validated scales for organizational research and diagn. China Light Industry Publishing, 2004, p.49-51.

[9]. Dail Lfields. A guide to validated scales for organizational research and diagn. China Light Industry Publishing, 2004, p. 14-15.

[10]. Shu cai Ma, Li li Li. An investigation into the current situation of special education teachers in gansu province. Chinese Journal of Special Education. (2018) No.2, p. 69-76.

[11]. Yan yan Yang, Xin bin Ge. Requirements, problems and suggestions of the training of special education teachers in northern guangdong. Journal of Modern Special Education. (2016) No. 4 , p. 48-52.

[12]. Jian sen Sheng. The enlightenment of the research on teachers' teaching efficacy to the growth of teachers. Education exploration. (2005) No. 1, p. 116-117.

[13]. Xiu fang Du, Ji lin Liu. Review on the research of teacher efficacy. Journal of shandong teachers' university (humanities and social sciences). Vol.47(2002) No. 3, p. 117-119.

[14]. Tong yuan Xing. An Analysis of the problems and causes of the Professional growth of Special Education Teachers. Contemporary Education Sciences. (2015) No. 16, p. 38-41.

[15]. Xiao Luo, Hong zhuan Zhang. Exploration on-the-job training of special education teachers in higher vocational colleges in China. Education and Vocation. (2016) No. 12, p. 76-78.

[16]. Fu yi Yang. An Investigation and analysis on teaching efficacy of teachers in special education schools in China. Global Education.Vol.48(2019) No. 2, p.118-128.

[17]. Ze qin Jin, Zuo shan Li, Jing Liu. Job burnout and teaching efficacy of common versus special educational teachers. Journal of Clinical Rehabilitative Tissue Engineering Research. Vol.11(2007) No. 52, p.10621-10624.

[18]. Lin Huang. Research on the relationships between organizational commitment of teachers and their job performance. Theory and Practice of Contemporary Education. Vol.7(2007) No.10, p.154-157. 